\title{
Optical absorption and fluorescent behaviour of titanium ions in silicate glasses
}

\author{
MANOJ KUMAR, AMAN UNIYAL, A P S CHAUHAN and S P SINGH* \\ Department of Ceramic Engineering, Institute of Technology, Banaras Hindu University, Varanasi 221 005, India
}

MS received 23 May 2002; revised 16 December 2002

\begin{abstract}
Titanium in normal melting conditions in air atmosphere present as $\mathrm{Ti}^{4+}$ ion in basic silicate glasses exhibited an ultra-violet cut-off in silicate glasses, viz. soda-magnesia-silica, soda-magnesia-limesilica and soda-lime-silica glasses. This indicates that $\mathrm{Ti}^{4+}$ ion can be a good replacement for $\mathrm{Ce}^{4+}$ ion in producing UV-absorbing silicate glasses for commercial applications. The wavelength maxima at which the infinite absorption takes place in glasses was found to be around $310 \mathrm{~nm}$ against Ti-free blank glass in UV-region. The mechanism of electronic transition from $\mathrm{O}^{2-}$ ligands to $\mathrm{Ti}^{4+}$ ion was suggested as $\mathrm{L} \rightarrow \mathrm{M}$ charge transfer. The low energy tails of the ultra-violet cut-off were found to obey Urbach's rule in the optical range 360$500 \mathrm{~nm}$. The fluorescence spectra of these glasses were also studied and based on the radiative fluorescent properties it was suggested that the soda-lime-silica glass containing $\mathrm{Ti}^{4+}$ ion with greater emission crosssection would emit a better fluorescence than the corresponding soda-magnesia-lime-silica and sodamagnesia-silica glasses. The shift of emission wavelengths maxima towards longer wavelength in titania introduced silicate glasses was observed on replacement of $\mathrm{MgO}$ by $\mathrm{CaO}$ which may be attributed due to an increase in basicity of the glass system.
\end{abstract}

Keywords. Optical; fluorescent characteristic; titania; silicate glasses; UV-visible range.

\section{Introduction}

In normal melting conditions titanium can be present in basic silicate glasses in air as furnace atmosphere in the form of $\mathrm{Ti}^{4+}$ ion whereas under strongly reducing conditions it can exist as $\mathrm{Ti}^{3+}$ ion (Kumar 1959; Bamford 1962, 1977; Bates 1962; Weyl 1967; Lee and Bruckner 1982; Paul 1982; Singh and Singh 2001). Several other systematic investigations have been carried out on optical absorption characteristics of glasses containing transition metal ions as well as their role as redox with particular reference to $3 \mathrm{~d}$ transition metal ions viz. $\mathrm{Cu}^{+} / \mathrm{Cu}^{2+}, \mathrm{Fe}^{2+} / \mathrm{Fe}^{3+}, \mathrm{Mn}^{2+} /$ $\mathrm{Mn}^{3+}, \mathrm{V}^{3+} / \mathrm{V}^{5+}$ and $\mathrm{Cr}^{3+} / \mathrm{Cr}^{6+}$ pairs, but information on the mechanism of charge transfer process resulting in the absorption bands due to $\mathrm{Ti}^{4+}$ ion in commercial type of silicate glasses had been lacking over past several years (Johnston 1964; Nath and Douglas 1965; Paul and Douglas 1965; Banerjee and Paul 1974; Singh et al 1978a,b; Duram and Fernandes Navarro 1985; Cable and Ziang 1989a,b; Bae and Weinberg 1991; Singh and Kumar 1992, 1995; Morinaga et al 1994; Singh and Singh 1998, 2000, 2001). However, Singh and Singh (2001) had studied the spectrochemical behaviour of charge transfer bands due to $d^{0}, d^{5}$ and $d^{10}$ ions in a sodium silicate glass

\footnotetext{
*Author for correspondence
}

and reported the intensity of the bands due to $\mathrm{Ti}^{4+}$ ion as $1.65 \times 10^{3}$ and $1.13 \times 10^{3} \mathrm{~g} \mathrm{~mol} / \mathrm{l} / \mathrm{cm}$ of glass at their wavelengths maxima of $250 \mathrm{~nm}$ and $290 \mathrm{~nm}$ in the glass, respectively. These authors suggested the mechanism of charge transfer from ligand to central metal ion in the binary sodium silicate glass based on the values of intensity of the bands. Further, they had also reported the appearance of UV-bands in the glass due to $\mathrm{Ce}^{4+}, \mathrm{V}^{5+}$ and $\mathrm{Cu}^{+}$ions and attributed the bands to ligand to metal $(\mathrm{L} \rightarrow \mathrm{M})$ charge transfer in $\mathrm{V}^{5+}$ ion and $\mathrm{Ce}^{4+}$ ion and metal to ligand to metal $(\mathrm{M} \rightarrow \mathrm{L} \rightarrow \mathrm{M})$ cooperative charge transfer in the case of $\mathrm{Cu}^{+}$ions $\left(\mathrm{Cu}^{+} \rightarrow \mathrm{O}\right.$ $\rightarrow \mathrm{Cu}^{2+}$ ), respectively in the glass (Singh et al 1986; Singh and Singh 2001).

Steele and Douglas (1965) suggested that in silicate glasses on the one hand ferrous ion is responsible for charge transfer band in UV region in between 200 and $230 \mathrm{~nm}$ with an intensity of $3 \times 10^{3} \mathrm{~g} \mathrm{~mol} / \mathrm{l} / \mathrm{cm}$, while on the other hand, in silicate and borate glasses ferric ion has strong charge transfer band with molar extinction coefficient of $7 \times 10^{3} \mathrm{~g} \mathrm{~mol} / \mathrm{l} / \mathrm{cm}$ centred at its wavelength maxima at around $230 \mathrm{~nm}$ in ultraviolet region. Nath et al (1965) studied the ultraviolet absorption characteristics of hexavalent chromium in alkali silicate glasses as well as aqueous alkaline chromate solution and in the light of identical absorption spectra of glasses and solutions containing chromium, they identified the presence 
of $\mathrm{Cr}^{6+}$ ions as chromate complex ions $\left(\mathrm{CrO}_{4}^{2-}\right)$. They reported the intensity of the bands due to $\mathrm{Cr}^{6+}$ ions as $4.2 \times 10^{3} \mathrm{~g} \mathrm{~mol} / 1 / \mathrm{cm}$ in a sodium silicate glass at its wavelength maxima of $370 \mathrm{~nm}$.

In the case of iron present in the silicate glass, the mechanism of charge transfer has been suggested as exchange of electrons in between $\mathrm{M} \rightarrow \mathrm{L} \rightarrow \mathrm{M}$ cooperative charge transfer in the glass (Steele and Douglas 1965; Wood and Remeika 1966). Whereas in the case of sodium silicate glass containing hexavalent chromium the mechanism of charge transfer has been reported as transfer of electron from oxygen ligand to central metal ion as $\mathrm{L} \rightarrow \mathrm{M}$ charge transfer (Nath et al 1965; Singh and Singh 2001). Paul (1982) had also studied the mechanism of charge transfer with mixed cerium-titanium redox in a sodium boroalumino silicate glass and suggested that the broad charge transfer band had arisen at about $345 \mathrm{~nm}$ due to cooperative charge transfer within $\mathrm{Ce}^{3+}-\mathrm{O}-\mathrm{Ti}^{4+}$ coloured chromophore. He also observed the optical absorption behaviour of $12 \mathrm{Na}_{2} \mathrm{O} \cdot 20 \mathrm{~B}_{2} \mathrm{O}_{3} \cdot 3 \mathrm{Al}_{2} \mathrm{O}_{3} \cdot 65 \mathrm{SiO}_{2}$ glass melted with 1.5 wt. $\% \mathrm{TiO}_{2}$ in the wavelength range 290 $450 \mathrm{~nm}$ and found that the low energy tail of the UV cutoff for $\mathrm{Ti}^{4+}$ ion obeyed the Urbach's rule for relation between $\log$ (absorbance/cm) vs frequency of radiation in the range of around $22000-27000 \mathrm{~cm}^{-1}$ in the glass. However, in the higher frequency range beyond $27000 \mathrm{~cm}^{-1}$ $(370 \mathrm{~nm})$ the deviation of the curve from linearity had indicated its tendency for an approach towards an UVband due to $\mathrm{Ti}^{4+}$ ion as marked by a sharp cut-off at around $300 \mathrm{~nm}$ also in the sodium alumino borosilicate glass even for higher concentration of titania than $0.1 \%$ by weight in the glass.

In the light of this the present study was undertaken with a view to investigate the optical absorption characteristics of titanium ions in soda-magnesia-silica, sodalime-silica and soda-magnesia-lime-silica glasses in the UV-visible region as well as to suggest the mechanism of transfer of electrons which result in the UV bands in the aforesaid optical range.

Since the phenomena of fluorescence in the visible region due to a characteristic species occur only when its absorption behaviour is ceased as such, studies on fluorescent behaviour of titanium ions was also undertaken in the proposed glasses here. Although several investigations had been carried out in the past to dictate the excitation and emission properties of rare earth ions in glasses but the studies on optical fluorescent characteristics of transition metal ions in glasses are still very small. However, in order to explore the possibilities for the presence of even traces of titanium in trivalent state due to its redox property in glasses (Johnston 1965), it was also planned to investigate the fluorescence spectra of the proposed silicate glasses doped with titania along with its optical transmission spectra as $\mathrm{Ti}^{3+}$ ion had been known to exhibit optical absorption as well as fluorescence characteristics in glasses.

\section{Experimental}

Silicate glasses having molar compositions: $20 \mathrm{Na}_{2} \mathrm{O} \cdot 10 \mathrm{MgO}$. $70 \mathrm{SiO}_{2}, \quad 20 \mathrm{Na}_{2} \mathrm{O} \cdot 10 \mathrm{CaO} \cdot 70 \mathrm{SiO}_{2}$ and $20 \mathrm{Na}_{2} \mathrm{O} \cdot 4 \mathrm{MgO}$. $6 \mathrm{CaO} \cdot 70 \mathrm{SiO}_{2}$, were selected as the base glass. For preparing the glass batches, analytical reagent grade $99.9 \%$ pure $\mathrm{BDH}$ sodium carbonate, calcium carbonate, Thomas and Baker $4 \mathrm{MgCO}_{3} \cdot \mathrm{Mg}(\mathrm{OH})_{2} \cdot n \mathrm{H}_{2} \mathrm{O}$ as well as acid washed natural quartz up to less than $0.001 \% \mathrm{Fe}_{2} \mathrm{O}_{3}$ impurities were used. Desired concentration of titanium as 500$1000 \mathrm{ppm} \mathrm{TiO}_{2}$ was introduced in the glass batches as analytical reagent grade titania. Silicate glasses doped with $\mathrm{TiO}_{2}$ were melted in a $100 \mathrm{ml}$ capacity platinum-2\% rhodium crucible. The crucible containing the glass batch was kept in a Globar rod electric furnace in air atmosphere at $1425^{\circ} \mathrm{C}$. The temperature was controlled within $\pm 10^{\circ} \mathrm{C}$ with an automatic R-type thermocouple temperature indicator-cum-controller. The glasses were melted for $\sim 6 \mathrm{~h}$ and then were cast and poured onto an aluminium plate. After cooling they were crushed and remelted in the furnace for another $4 \mathrm{~h}$ to ensure homogeneity. They were taken out of the furnace and poured into a rectangular mould on an aluminium plate and annealed at $500^{\circ} \mathrm{C}$ for $1 \mathrm{~h}$ and cooled to room temperature slowly by controlling the rate of cooling. After grinding and polishing the transmission spectra of the glass samples were recorded on a Varian-Cary 2390 recording spectrophotometer in the UV-visible region against a blank glass prepared without titania. The thicknesses of the glass samples were measured and their densities were also determined by Archimedes principle at room temperature. The fluorescence spectra of the glass samples were recorded on a Perkin-Elmer LS-45 fluorescence spectrometer.

\section{Results and discussion}

Results presented in figure 1 show the optical transmission spectra of titanium ions present in soda-magnesiasilica, soda-lime-silica and soda-magnesia-lime-silica glasses. The relation between $\log$ (absorbance/cm) and wave number $\left(\mathrm{cm}^{-1}\right)$ indicate the verification of Urbach's rule as given in (1) where the low energy tail of the UV cut-off follows a linear behaviour in the optical range of around 20000-28000 $\mathrm{cm}^{-1}$ :

$$
\log (\text { absorbance } / \mathrm{cm})=A+B v,
$$

where $A$ and $B$ are constants and $v$ the frequency of radiation. The optical transmission spectra of glasses containing titania show a sharp ultraviolet cut-off at around $310 \mathrm{~nm}$ for all these silicate glasses, viz. $\mathrm{Na}_{2} \mathrm{O}-\mathrm{MgO}-\mathrm{SiO}_{2}$, $\mathrm{Na}_{2} \mathrm{O}-\mathrm{CaO}-\mathrm{MgO}-\mathrm{SiO}_{2}$ and $\mathrm{Na}_{2} \mathrm{O}-\mathrm{CaO}-\mathrm{SiO}_{2}$, with reference to their blank glass samples which is attributed due to the presence of $\mathrm{Ti}^{4+}$ ion in the glass. Although the ultraviolet absorption of $\mathrm{Ti}^{4+}$ ion dependent upon the glass composition originates from different points of 
ordinate in figure 1 but it shows an UV cut-off at around $\sim 310 \mathrm{~nm}$ showing infinite ultraviolet absorption at zero transmission. The transmission spectra of glasses were recorded in UV-visible region $(200-800 \mathrm{~nm})$ in order to explore the possibilities for the presence of the $\mathrm{Ti}^{3+}$ ion but the optical transmission curves do not show sign of minimum transmission (\%) due to trivalent titanium in the visible range at any particular wavelength maxima. At this stage it is ensured that $\mathrm{Ti}^{3+}$ ion is not at all present in the glass to show any absorption band in the visible region at a $\lambda_{\max }$. So the entire amount of titanium is present in the glass in its tetravalent state.

In order to marking the UV-bands for $\mathrm{Ti}^{4+}$ ion having high intensities as found earlier to be of the order of around $10^{3} \mathrm{~g}-\mathrm{mol} / \mathrm{l} / \mathrm{cm}$ of a $3 \mathrm{Na}_{2} \mathrm{O} \cdot 7 \mathrm{SiO}_{2}$ in ultraviolet region (Singh and Singh 2001), the concentration of $\mathrm{TiO}_{2}$ was kept quite low $(0 \cdot 05-0 \cdot 10 \mathrm{wt} \%)$, but the absorption of the UV-radiation even in thinner glass samples at $\lambda_{\max }$ at $\sim 310 \mathrm{~nm}$ was found to be infinite showing zero transmission in the curve (figure 1). At this stage it is mentioned that $\mathrm{Ti}^{4+}$ ion would be a good substitute for $\mathrm{Ce}^{4+}$ ion for producing UV absorbing glasses for commercial applications as titania being cheaper than ceria. The deviation of the curves from linearity indicate that the UVband for $\mathrm{Ti}^{4+}$ ion is being approached in the glass (figure 2 ). However, it would be interesting to refer to the work of Steele and Douglas $(1965,1966)$ who studied using Lambert-Beer's law the effect of absorption of a blank sodium silicate glass contaminated with very small proportion of ferric iron on the UV-absorption characteris-

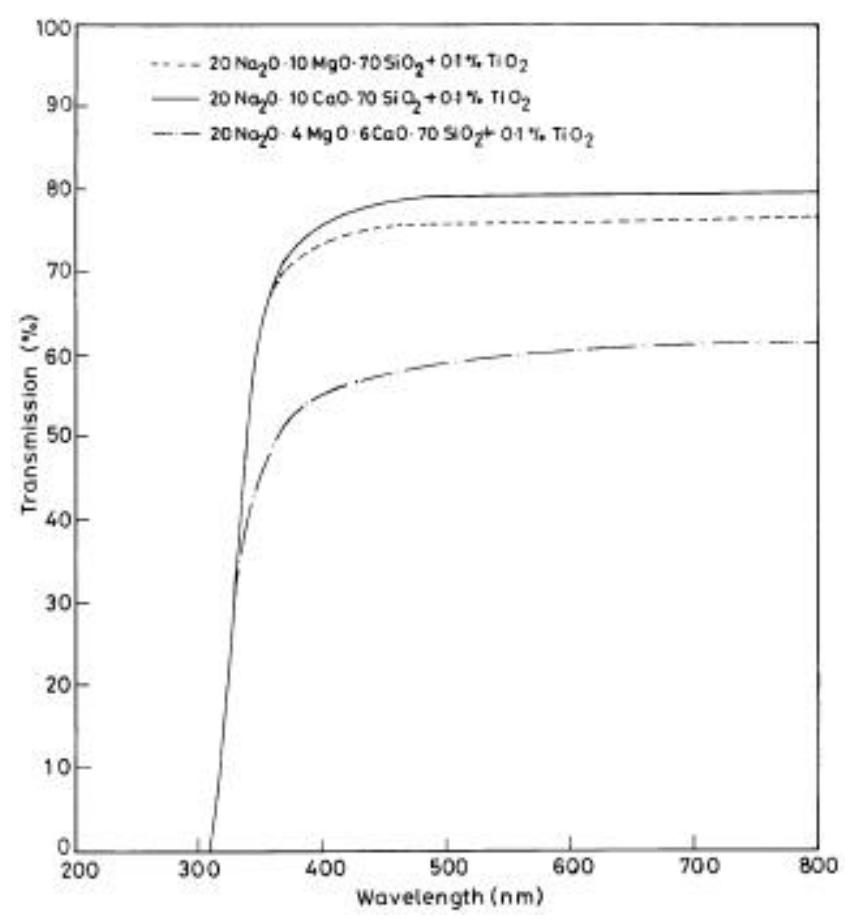

Figure 1. Optical transmission spectra of titania doped silicate glasses. tics of the silicate glasses doped with iron in the range of 200-350 nm (figure 3). The authors reported that the background absorption of the blank glass was found to decrease with increasing wavelength of the UV-radiations and showing an almost negligible effect in the range of around 310-330 $\mathrm{nm}$ as presented in figure 3. Further, they mentioned that the non-bridging oxygen apart from ferric iron in the glass probably might be contributing to the UV cut-off at around $210 \mathrm{~nm}$ causing an exciton charge transfer to the neighbouring positive ion in the glass. The slight levelling over the range of $230-280 \mathrm{~nm}$ was probably due to ferric iron impurity. The intensity of the background absorption due to ferric iron impurities was more significant in this range and also greater at around $230 \mathrm{~nm}$ in the silicate glass. Whereas it did not affect the iron spectra as $\mathrm{Fe}^{3+}$ ion had no absorption in the longer range of UV-radiations $(\sim 310-330 \mathrm{~nm})$. In view of this it is clearly mentioned herewith that the UV cut-off at $\sim 310 \mathrm{~nm}$ is definitely due to charge transfer from oxygen ligands to $\mathrm{Ti}^{4+}$ ion in the present silicate glasses as the effect of the background impurities due to contamination of ferric iron in the glass was almost negligible and insignificant at around this wavelength. Hence the use of the semiconductor grade silica was not so required at this stage irrespective of whether the chemically bonded traces of iron impurities were present in the acid washed quartz.

The comparison of the energy of a redox pair with another has been already observed and practically become a productive process with reference to mixed redox interaction in glasses at high temperature like redox titrations in aqueous acidic or alkaline solutions in air atmosphere at room temperature. Although the melting conditions in glasses such as high temperature and base glass compositions are different for redox reactions from aqueous media at room temperature in atmospheric

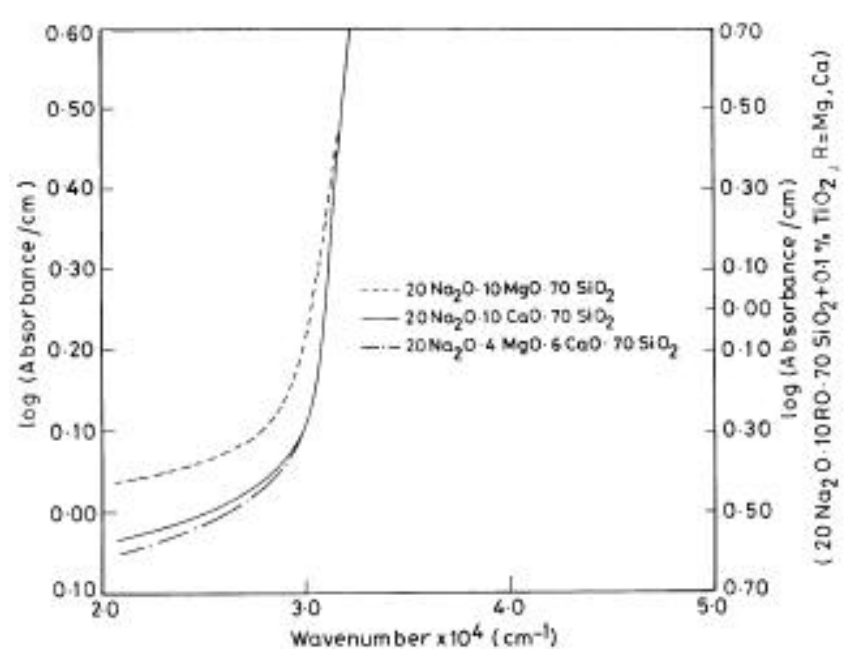

Figure 2. Verification of Urbach's rule by relation between $\log ($ absorbance $/ \mathrm{cm})$ and frequency of UV-radiation for $\mathrm{Ti}^{4+}$ ion in silicate glasses. 
air. The production of ferro-manganese amber glass, physico-chemical decolourization of intense ferrous blue colour by manganic ion, preparation of heat absorbing glass by thermo reduction of ferric iron to ferrous ion with stannous tin, development of emerald green colour due to trivalent chromium by reducing $\mathrm{Cr}^{6+}$ ion with $\mathrm{Sn}^{2+}$ ion and chemical decolorization of ferrous blue colour by oxidizing it into ferric straw yellow with $\mathrm{As}^{5+}$ ion in glasses as well as preparation of $\mathrm{Mn}^{3+}+\mathrm{Cr}^{3+}$ black colour are some of the common examples of redox reactions where their redox potentials have played a vital role as per the following reactions in glass melts.

$$
\begin{aligned}
& \mathrm{Fe}^{2+}+\mathrm{Mn}^{3+} \rightleftharpoons \mathrm{Fe}^{3+}+\mathrm{Mn}^{2+}, \\
& 2 \mathrm{Fe}^{3+}+\mathrm{Sn}^{2+} \rightleftharpoons 2 \mathrm{Fe}^{2+}+\mathrm{Sn}^{4+}, \\
& 2 \mathrm{Cr}^{6+}+3 \mathrm{Sn}^{2+} \rightleftharpoons 2 \mathrm{Cr}^{3+}+3 \mathrm{Sn}^{4+}, \\
& 2 \mathrm{Fe}^{2+}+\mathrm{As}^{5+} \rightleftharpoons 2 \mathrm{Fe}^{3+}+\mathrm{As}^{3+}, \\
& 3 \mathrm{Mn}^{2+}+\mathrm{Cr}^{6+} \rightleftharpoons 3 \mathrm{Mn}^{3+}+\mathrm{Cr}^{3+}
\end{aligned}
$$

The development of photosensitive copper ruby, silver yellow and gold ruby colloidal colours in glasses in presence of $\mathrm{CeO}_{2}$ as sensitizer in the glass melts where the $\mathrm{Ce}^{3+} / \mathrm{Ce}^{4+}$ redox species played an important part, had

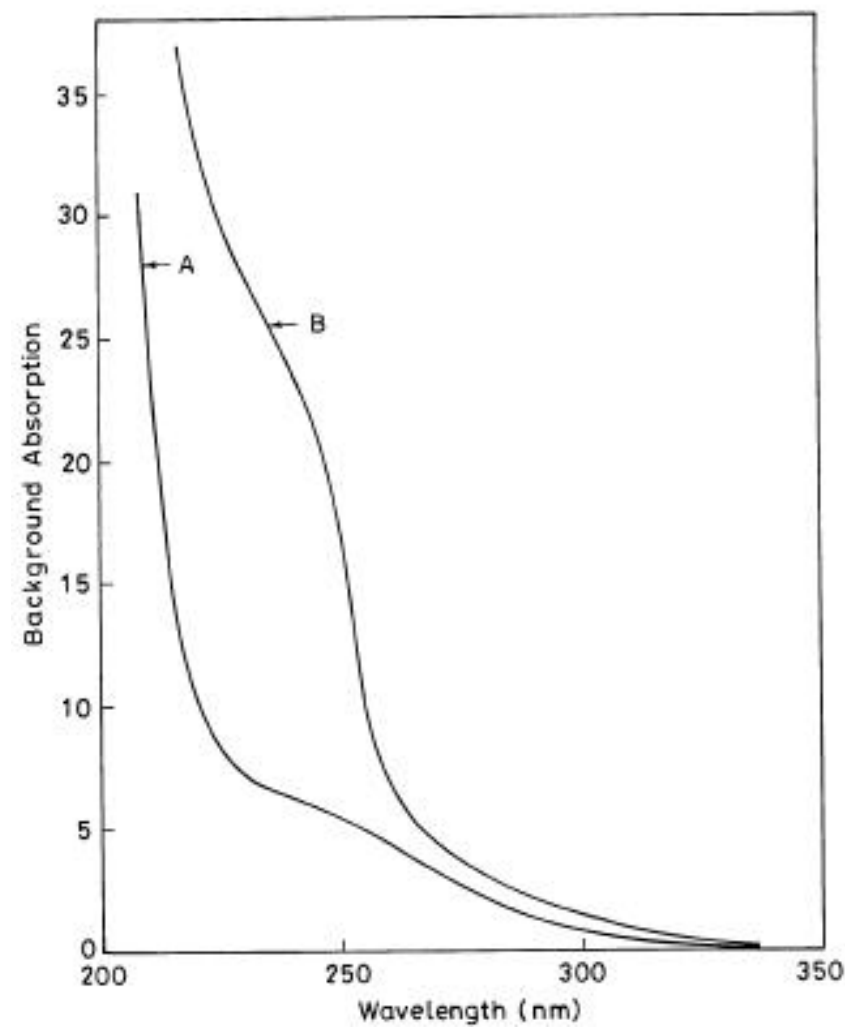

Figure 3. Relation between background absorption vs wavelength for a $30 \mathrm{Na}_{2} \mathrm{O} \cdot 70 \mathrm{SiO}_{2}$ (A) blank glass and (B) glass doped with iron (Steele and Douglas 1966). been done by mixed $\left(\mathrm{Cu}^{+} / \mathrm{Cu}\right)+\left(\mathrm{Ce}^{3+} / \mathrm{Ce}^{4+}\right) ;\left(\mathrm{Ag}^{+} / \mathrm{Ag}\right)+$ $\left(\mathrm{Ce}^{3+} / \mathrm{Ce}^{4+}\right)$ and $\left(\mathrm{Au}^{+} / \mathrm{Au}\right)+\left(\mathrm{Ce}^{3+} / \mathrm{Ce}^{4+}\right)$ redox interactions (Dwivedi and Nath 1977, 1978, 1980). So was the case of $\mathrm{Ti}^{3+} / \mathrm{Ti}^{4+}$ and $\mathrm{Ce}^{3+} / \mathrm{Ce}^{4+}$ redox interactions as per the reaction

$$
\mathrm{Ce}^{3+}+\mathrm{Ti}^{4+} \rightleftharpoons \mathrm{Ce}^{4+}+\mathrm{Ti}^{3+},
$$

for preparation of cerium-titanium intense yellow colour in glass. Kuhl et al (1938) tabulated redox species commonly used in the glass in order of increasing their redox potentials as $\mathrm{Cr}^{3+} / \mathrm{Cr}^{6+}>\mathrm{Mn}^{2+} / \mathrm{Mn}^{3+}>\mathrm{Ce}^{3+} / \mathrm{Ce}^{4+}>\mathrm{Cu} /$ $\mathrm{Cu}^{+}>\mathrm{As}^{3+} / \mathrm{As}^{5+}>\mathrm{Fe}^{2+} / \mathrm{Fe}^{3+}>\mathrm{Sn}^{2} / \mathrm{Sn}^{4+}>\mathrm{Ti}^{3+} / \mathrm{Ti}^{4+}$ which had dictated that any reduced state of a redox having lower potential would be oxidized by the oxidized state of another with higher potential which was placed above it in the electrochemical series. Similar table prepared on the basis of standard thermodynamic data for pure oxides was also reported by Tress (1960).

In silicate glasses because of the random network model of $\left[\mathrm{SiO}_{4}\right]$ tetrahedra $\mathrm{Ti}^{4+}$ ion even having greater ionic radii could form tetrahedra and enter into the network resulting in a random packing of tetrahedra. The analysis of an infra-red spectra of a titania silica glass prepared with $10 \mathrm{wt} \% \quad \mathrm{TiO}_{2}$ by Smith and Condrate (1975) had shown earlier that the IR band at around $735 \mathrm{~cm}^{-1}$ out of the four bands marked at 940, 735, 360 and $240 \mathrm{~cm}^{-1}$ could be assigned due to vibrational mode of the tetrahedral $\left[\mathrm{TiO}_{4}\right]$ group in silica glass. The tetrahedral coordination of $\mathrm{Ti}^{4+}$ ion deduced as above was in accordance with the previous findings of Evans (1970) that $\mathrm{Ti}^{4+}$ ion was present as four-fold coordinated $\mathrm{Si}^{4+}$ ion in silicate glasses. There was no fundamental mode with characteristic frequencies to indicate octahedral coordination of titanium in the glass.

Since the glasses melted with titania had contained only tetravalent titanium as an ultraviolet absorbing species at $\sim 310 \mathrm{~nm}$, in the light of the present justification, therefore, the probable mechanism of charge transfer is suggested herewith as the transfer of an electron from oxygen $\left(\mathrm{O}^{2-}\right)$ ligands to fill up the vacant $d^{0}$-orbital of $\mathrm{Ti}^{4+}$ ion $(\mathrm{L} \rightarrow \mathrm{M})$ present in the glass as $\left[\mathrm{TiO}_{4}\right]^{4-}$ complex ion which is based on the facts. The presence of similar charge transfer species such as $\left[\mathrm{CrO}_{4}\right]^{2-},\left[\mathrm{CeO}_{4}\right]^{4-}$ and $\left[\mathrm{VO}_{4}\right]^{3-}$ had already been reported in the silicate glass by previous workers (Nath et al 1965; Singh et al 1986; Singh and Singh 2001). Although the $\lambda_{\max }$ at around $310 \mathrm{~nm}$ is the same in the curve (figure 1) but the intensity of $\mathrm{Ti}^{4+}$ bands is expected to be dependent upon the glass composition and mixed effect of these alkaline earth oxides as well at the wavelength maxima. The applicability of Urbach's rule as tested and verified for $\mathrm{Ti}^{4+}$ ion in glasses (figure 2) follows similar patterns as it was found in the case of other charge transfer species like $\mathrm{Cu}^{+}, \mathrm{V}^{5+}, \mathrm{Ce}^{4+}, \mathrm{Fe}^{3+}$ and $\mathrm{Cr}^{6+}$ ions in glasses (Nath et al 1965; Singh et al 1986; Singh and Singh 2001). The present results with lower concentration of titania are in con- 
formity to silicate glass containing higher concentration of $1.5 \mathrm{wt} \% \mathrm{TiO}_{2}$ as referred to in figure 4 after Paul (1982). They are also in close analogy to the results reported in the fluorophosphate glass melted with titanium for an UV-band at $\sim 300 \mathrm{~nm}$ due to $\mathrm{Ti}^{4+}-\mathrm{F}^{-}$charge transfer process (Fuxi 1992).

The ability to generate spectrophotometrically active reduced species under non-equilibrium condition is of vital importance for determining the coordinations and symmetries of the newly formed ions such as $\mathrm{Ti}^{3+}$ in glasses. The formation of $\mathrm{Ti}^{3+}$ ions was observed earlier as a product of irradiation of $\mathrm{Ti}^{4+}$ ion present in the glass and presumably located in the same oxygen environment possessed by the original $\mathrm{Ti}^{4+}$ ion before the occurrence of electron capture (Smith and Cohen 1963; Wong and Angell 1976). The trivalent titanium being $3 d^{1}$ ion should exhibit a ligand field spectrum the form of which would identify directly the oxygen coordination, but $\mathrm{Ti}^{3+}$ ion was not observed presently in glasses at all.

The excitation and emission spectra of $\mathrm{Ti}^{4+}$ ions present in the glasses have been given in figures 5 and 6 , respectively. The relative intensity of emitted radiations was found to be of the order of around $1.02 \rightarrow$ $1.03 \times 10^{3}$. The excitation spectra in the present ternary silicate glasses as in figure 5 show that an excitation at around $310 \mathrm{~nm}$ which corresponds to the $\mathrm{Ti}^{4+}\left(3 d^{0}\right)$ $\leftarrow \mathrm{O}^{2-}\left(2 s^{2} 3 p^{6}\right)$ charge transfer band might impart an intense fluorescence radiative emission transition from an excited energy level to the ground level due to $\mathrm{M} \rightarrow \mathrm{L}$ charge transfer. This process of transition from excited $\mathrm{Ti}^{4+}$ ion to $\mathrm{O}^{2-}$ ligands exhibits the fluorescent behaviour of $\mathrm{Ti}^{4+}$ ion in glasses which might be attributed due to energy transfer by ion-phonon coupling. Similar observations in form of $\mathrm{Ti}^{4+}-\mathrm{F}^{-}-\mathrm{Ti}^{3+}$ charge transfer were also reported earlier in reduced fluorophosphate glass which contained both the $\mathrm{Ti}^{3+}$ and $\mathrm{Ti}^{4+}$ ions (Fuxi 1992). Park and Webb (1972) as well as Annapurna et al (2000)

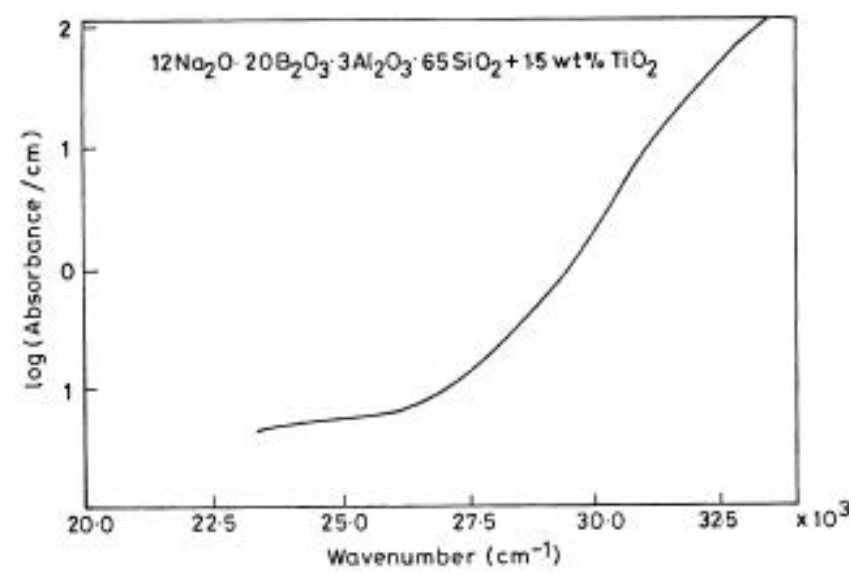

Figure 4. Optical absorption characteristics of a sodium boro-alumino silicate glass containing $1.5 \mathrm{wt} \% \quad \mathrm{TiO}_{2}$ (Paul 1982). studied the UV-excitation of $\mathrm{Cu}^{+}$ion from $3 d^{10}$ configuration to $3 d^{9} 4 s^{1}$ and reported the fluorescent transition as the phonon assisted greenish blue emission the broader visible bands for which at around $500 \mathrm{~nm}$ were attributed due to spin forbidden transition from excited ${ }^{3} \mathrm{Eg}$ $\left(3 d^{9} 4 s^{1}\right) \rightarrow{ }^{1} \mathrm{Ag}\left(3 d^{10}\right)$ ground level in phosphate and zinc borosilicate glasses.

When the light radiation interacts with an electronic system in an ionic state the radiative absorption or emission transition between two energy levels $\psi_{a}$ and $\psi_{b}$ is induced. The spontaneous emission transition probability, $A\left(\psi_{b} \rightarrow \psi_{a}\right)$ from the excited ion level $\psi_{b}$ to a level $\psi_{a}$ can be approximately given by the following equation (Paul 1982; Fuxi 1992)

$$
A\left(\psi_{b} \rightarrow \psi_{a}\right)=\frac{8 v^{2} \times 10^{6}}{e^{2}},
$$

where $v$ is the frequency of emission transition and $e$ the charge of the electron. The stimulated emission crosssection for each emission band $\left(\sigma_{\mathrm{se}}\right)$ in the present silicate glasses for the same excitation wavelength was calculated using the equation (Fuxi 1992)

$$
\sigma_{\mathrm{se}}=\left[\frac{\lambda^{4}}{8 \pi c n^{2} \Delta \lambda}\right] \mathrm{A}\left(\psi_{b} \rightarrow \psi_{a}\right),
$$

where $\Delta \lambda$ is the effective half band width and $\lambda$ the emission band position as well as $n$ is the refractive index of

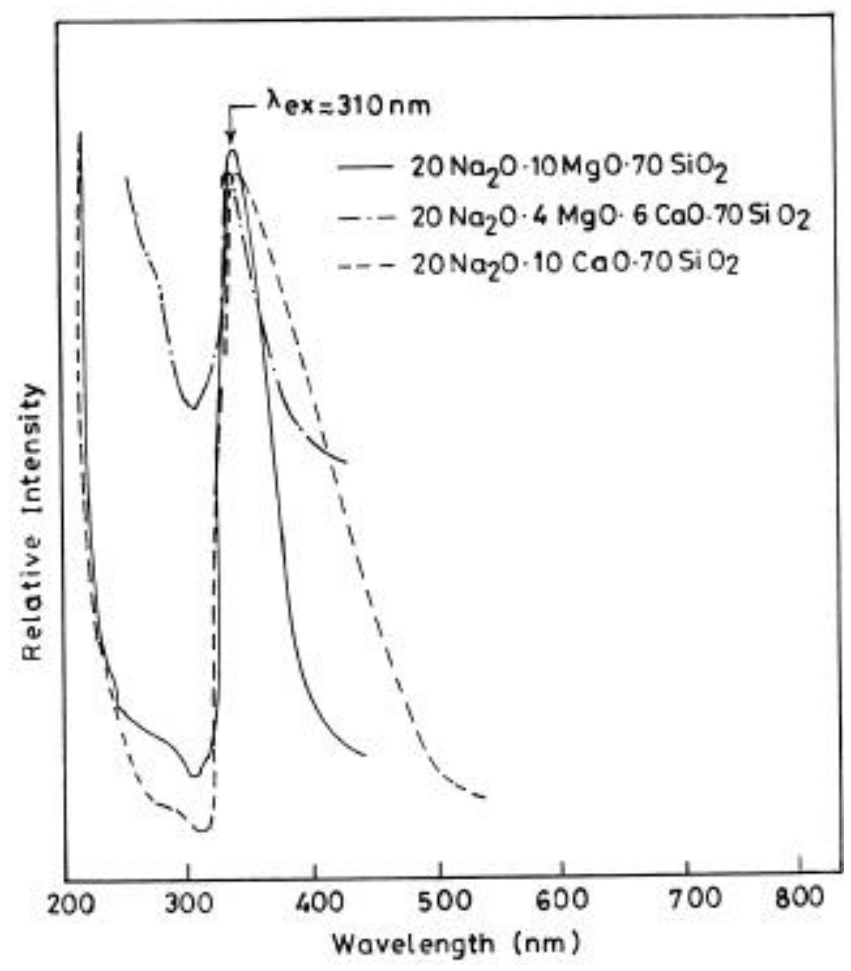

Figure 5. Excitation spectra of silicate glasses doped with $\mathrm{TiO}_{2}$. 
Table 1. Physical properties and stimulated emission cross sections $\left(\sigma_{\mathrm{se}}\right)$ of $\mathrm{Ti}^{4+}$-doped alkali-alkaline earth-silicate glasses.

\begin{tabular}{lccc}
\hline Physical properties & $\begin{array}{c}20 \mathrm{Na}_{2} \mathrm{O} \cdot 10 \mathrm{MgO} \cdot \\
70 \mathrm{SiO}_{2}\end{array}$ & $\begin{array}{c}20 \mathrm{Na}_{2} \mathrm{O} \cdot 4 \mathrm{MgO} \cdot \\
6 \mathrm{CaO} \cdot 70 \mathrm{SiO}_{2}\end{array}$ & $\begin{array}{c}20 \mathrm{Na}_{2} \mathrm{O} \cdot 10 \mathrm{CaO} \cdot \\
70 \mathrm{SiO}_{2}\end{array}$ \\
\hline Concentration of $\mathrm{TiO}_{2}($ wt. $\%)$ & $0 \cdot 100$ & $0 \cdot 100$ & $0 \cdot 100$ \\
Refractive index $(n)$ & $1 \cdot 511$ & $1 \cdot 520$ & 1.532 \\
Density $\left(d, \mathrm{mg} / \mathrm{cm}^{3}\right)$ & $2 \cdot 474$ & $2 \cdot 478$ & $2 \cdot 488$ \\
Reflection loss $(R \%)\left[R=(n-1 / n+1)^{2}\right]$ & $4 \cdot 120$ & $4 \cdot 250$ & 4.410 \\
Excitation wavelength, $\lambda$ ex $(\mathrm{nm})$ & 310 & 310 & 310 \\
Emission peak position, $\lambda(\mathrm{nm})$ & 326 & 418 & 425 \\
Emission band width, $\Delta \lambda(\mathrm{nm})$ & $10 \cdot 0$ & $12 \cdot 5$ & $12 \cdot 5$ \\
Stimulated emission cross-section, & & 6.91 & $7 \cdot 03$ \\
$\quad \sigma_{\mathrm{se}} \times 10^{-32}\left(\mathrm{~cm}^{2}\right)$ & $5 \cdot 30$ & & \\
\hline
\end{tabular}

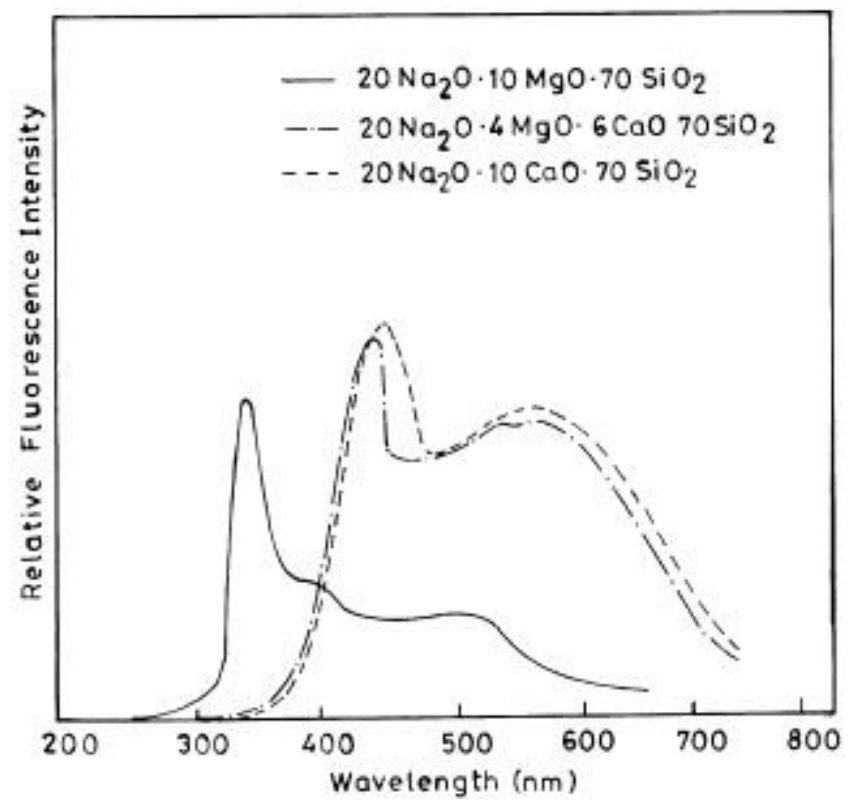

Figure 6. Emission spectra of silicate glasses doped with $\mathrm{TiO}_{2}$.

the glass. The values of stimulated emission cross-section $\left(\sigma_{\mathrm{se}} \mathrm{cm}^{2}\right)$ presented in table 1 was found to increase from $5.30 \times 10^{32}$ to $7.03 \times 10^{32}$ with increasing basicity or oxygen ion activity of the ternary silicate glass on replacing $\mathrm{MgO}$ by $\mathrm{CaO}$. The other physical parameters have also been given in table 1 . The order of magnitude of these results follow the similar pattern reported earlier in ternary silicate, phosphate and alkali-magnesia-alumino silicate glasses containing rare earth $\mathrm{Nd}^{3+}$ and $\mathrm{Sm}^{3+}$ ions (Fuxi 1992; Annapurna et al 1999). Further, it is concluded that a soda-lime-silica glass containing $\mathrm{Ti}^{4+}$ ion with higher $\sigma_{\mathrm{se}}\left(\mathrm{cm}^{2}\right)$ value would emit a better radiative fluorescence than the corresponding soda-magnesialime-silica and soda-magnesia-silica glasses with their lower values. The present results presented in table 1 are also in conformity with the results obtained by Sreenivasulu and Rao (2001) in fluoroborophosphate glasses prepared with $\operatorname{Pr}^{3+}$ ion who mentioned that an increase in the value of emission cross-section would lead to a better fluorescence emissivity in glasses at room temperature.

In oxide glasses the shifting of emission bands obtained for active sites is not only dependent upon temperature but also it depends upon the glass composition which can be marked from the peak position and the band width as reported previously for other ions and evident from figure 6 for $\mathrm{Ti}^{4+}$ ion at room temperature. In case of glasses particularly at least at room temperature the coupling between ions and phonons becomes stronger for cross relaxation and the interaction between them would result in emission by energy transfer. The same may not take place probably at lower temperature. The nature and intensity of the fluorescent $\mathrm{Ti}^{4+}$ centre in the glass is its specific characteristics like other species which depends upon its band position, temperature and the glass composition, its emission spectra would not be generally influenced due to the presence of background small iron impurities in the glass till it is overlapped by them which was not observed during present investigation.

\section{Acknowledgements}

The authors gratefully dedicate this work to the Department of Ceramic Engineering, Institute of Technology, and they are also thankful to the Director, Institute of Technology, Banaras Hindu University, Varanasi, for providing the necessary facilities for the present work.

\section{References}

Annapurna K, Dwivedi R N, Kumar A, Chaudhuri A K and Buddhudu S 1999 Spectrochim. Acta 56103

Annapurna K, Kumar A, Dwivedi R N, Hussain N S and Buddhudu S 2000 Mater. Letts 4523

Bae B S and Weinberg M C 1991 J. Am. Ceram. Soc. 743039

Bamford C R 1962 Phys. Chem. Glasses 36189

Bamford C R 1977 in Glass science and technology (New York: Elsevier) 254 
Banerjee S and Paul A 1974 J. Am. Ceram. Soc. 57286

Bates T 1962 Modern aspect of vitreous state (ed.) J D Mackenzie (London: Butterworths) 2 p. 235

Cable M and Ziang Z D 1989a Glastech. Ber. 62382

Cable M and Ziang Z D 1989b Phys. Chem. Glasses 30237

Duram A and Fernandez Navarro J M 1985 Phys. Chem. Glasses 26126

Dwivedi R N and Nath P 1977 Cent. Glass. Ceram. Res. Inst. Bull. 2475

Dwivedi R N and Nath P 1978 Cent. Glass. Ceram. Res. Inst. Bull. 255

Dwivedi R N and Nath P 1980 Trans. Indian Ceram. Soc. 3923

Evans D L 1970 J. Am. Ceram. Soc. 53418

Fuxi G 1992 Optical and spectroscopic properties of glass (New York: Springer-Verlag) p. 155

Johnston W D 1964 J. Am. Ceram. Soc. 47198

Johnston W D 1965 J. Am. Ceram. Soc. 48184

Kuhl C, Rudow H and Weyl W A 1938 Sprechsaal 71118

Kumar S 1959 Cent. Glass Ceram. Res. Inst. Bull. 6399

Lee V J H and Bruckner R 1982 Glastech. Ber. 55219

Morinaga K, Yoshida H and Takebe H 1994 J. Am. Ceram. Soc. 773113

Nath P and Douglas R W 1965 Phys. Chem. Glasses 6197

Nath P, Paul A and Douglas R W 1965 Phys. Chem. Glasses 6 203

Park S and Webb R S 1972 Phys. Chem. Glasses 13157
Paul A 1982 Chemistry of glasses (New York: Chapman and Hall) 1st. ed. pp 230, 234, 250

Paul A and Douglas R W 1965 Phys. Chem. Glasses 6207

Singh R S and Singh S P 1998 Phys. Chem. Glasses 39140

Singh R S and Singh S P 2000 Trans. Indian Ceram. Soc. 5947

Singh R S and Singh S P 2001 J. Mater. Sci. 361555

Singh S P and Kumar A 1992 Phys. Chem. Glasses 2361

Singh S P and Kumar A 1995 J. Mater. Sci. 302999

Singh S P, Prasad G and Nath P 1978a Cent. Glass Ceram. Res. Inst. Bull. 2538

Singh S P, Prasad G and Nath P 1978b J. Am. Ceram. Soc. 61 377

Singh S P, Pyare R and Nath P 1986 in Collected papers XIV int. cong. on glass (Kolkata: Indian Ceramic Society) 1 p. 215

Smith C F Jr and Condrate R A 1975 Appl. Spectrosc. 2979

Smith H L and Cohen A J 1963 Phys. Chem. Glasses 4173

Sreenivasulu M and Rao A S 2001 Phys. Chem. Glasses 42397

Steele F N and Douglas R W 1965 Phys. Chem. Glasses 6246

Steele F N 1966 Absorption of iron in glasses, Ph D thesis, University of Sheffield, UK

Tress H J 1960 Phys. Chem. Glasses 1196

Weyl W A 1967 Coloured glasses (Sheffield, UK: Society of Glass Technology)

Wong J and Angell C A 1976 Glass structure by spectroscopy (New York: Marcel Dekker) p. 389

Wood D L and Remeika J P 1966 J. Appl. Phys. 371232 